\title{
Oral Ranitidine in Molluscum Contagiosum: A Novel Common Treatment Modality for a Common Disease
}

\author{
Chitalia AJ1* ${ }^{*}$, Agarwal SA ${ }^{2}$, Pilani $A^{1}$ and Madke B ${ }^{3}$ \\ ${ }^{1}$ Consultant Dermatologist and Hair Transplant Surgeon at ASSURE Skin and Hair \\ Clinic, India \\ ${ }^{2}$ Consultant Dermatologist at Elite Clinic, India \\ ${ }^{3}$ Associate professor at Dermatology Venereology and Leprosy Jawaharlal Nehru \\ medical college and AVBR Hospital Sawangi Meghe Wardha, India
}

Case Report

Volume 3 Issue 3

Received Date: November 27, 2018

Published Date: December 17, 2018

DOI: $10.23880 /$ cdoaj-16000166

*Corresponding author: Dr Jill Chitalia, B/705- Vasant Apartments, plot no 65-68, Garodia Nagar, Ghatkopar(East), Mumbai-400077, India, Tel: +91 9819142525; Email: jillchitalia@gmail.com

\begin{abstract}
Molluscum contagiosum[MC] is one of the most common viral infections in a child. It is usually a benign and self-limiting condition, but treatment is required due to risk of transmission and cosmetic concerns. There are many therapies available including effective painful invasive methods (cryo, curettage) and less efficacious topical agents. However most of them are associated with pain, irritation and scarring, which are not well tolerated in children. There are studies showing efficacy of oral cimetidine in children with MC. We thus extrapolated its immunomodulatory effect to ranitidine and treated a child with recurrent multiple facial molluscums with oral ranitidine $(5 \mathrm{mg} / \mathrm{kg} / \mathrm{day}$ in two divided doses) for 8weeks. Our patient showed complete clearance in 6weeks with no recurrence even after 2 months of stopping therapy. Thus we conclude that oral ranitidine should be considered as a simple, effective and safe alternative treatment for widespread, or recurrent MC in immunocompetent children.
\end{abstract}

Keywords: Oral ranitidine; Molluscum Contagiosum; Children

\section{Introduction}

Molluscum contagiosum [MC] is one of the most common viral infections in a child. It is usually a benign and self-limiting condition. However, fear of transmission to other kids leading to exclusion from school activities and also cosmetic concerns demands active treatment of MC. There are multiple treatment modalities available ranging from destructive painful methods like curettage, electrocauterisation, cryotherapy, chemical cauterization with trichloroacetic acid or salicylic acid or potassium hydroxide and topical retinoids to immunomodulators like oral cimetidine and topical imiquimod [1]. Destructive methods may be associated with pain, irritation, scarring, pigmentation and sometimes recurrence [1]. A survey of parents of children with MC found that they were mainly concerned about scarring \& pain [2]. Treatment of children with multiple molluscums 
on face becomes more challenging in view of the poor tolerance to painful methods and recurrence as a common side effect. Hence a safe and effective oral immunomodulator for treating multiple molluscums in a child is the need of an hour. We present a case of child with multiple molluscums on face successfully treated with a simple immunomodulator-oral ranitidine.

\section{Case Report}

An 8 year old male presented with multiple pearly white umbilicated papules on face ranging from 0.1-0.5 $\mathrm{cm}$ in size since 1month (Figures $1 \mathrm{a} \& 1 \mathrm{~b}$ ). He was diagnosed clinically as molluscum contagiosum and treated with needling and curettage of all lesions (Figure 2).

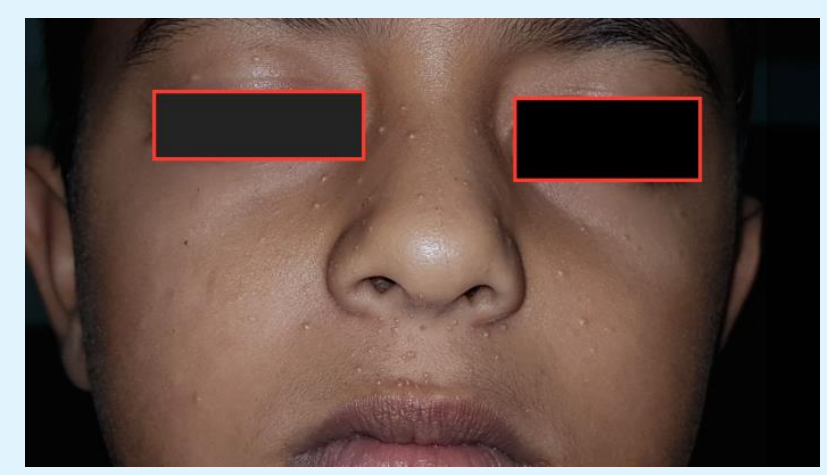

Figure 1a: Multiple Pearly White and Skin Coloured Papules on Face.

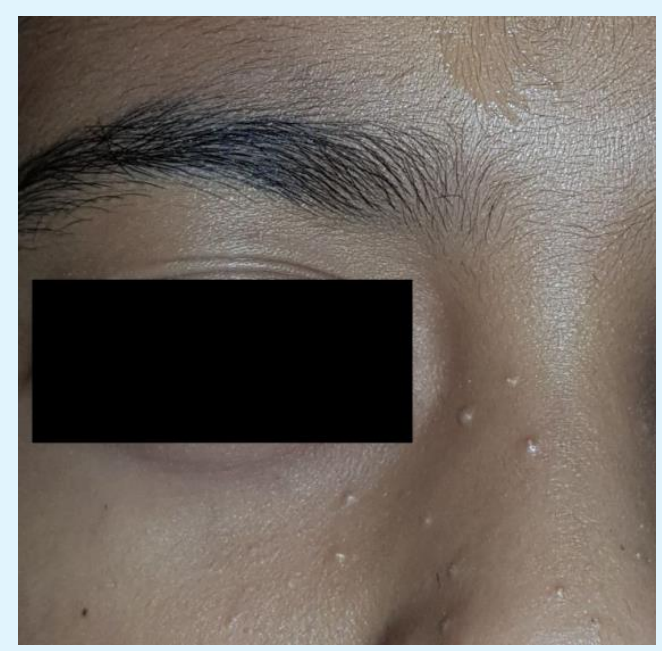

Figure 1b: Multiple Pearly White and Skin Coloured Umbilicated Papules.

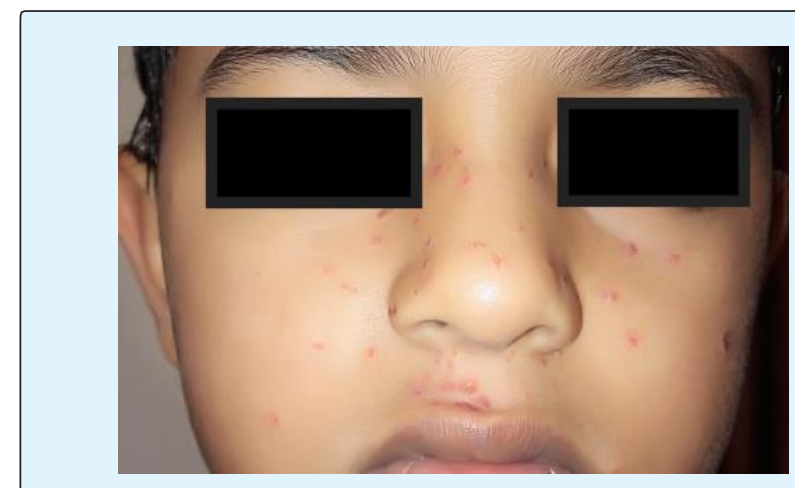

Figure 2: Post curettage of all lesions.

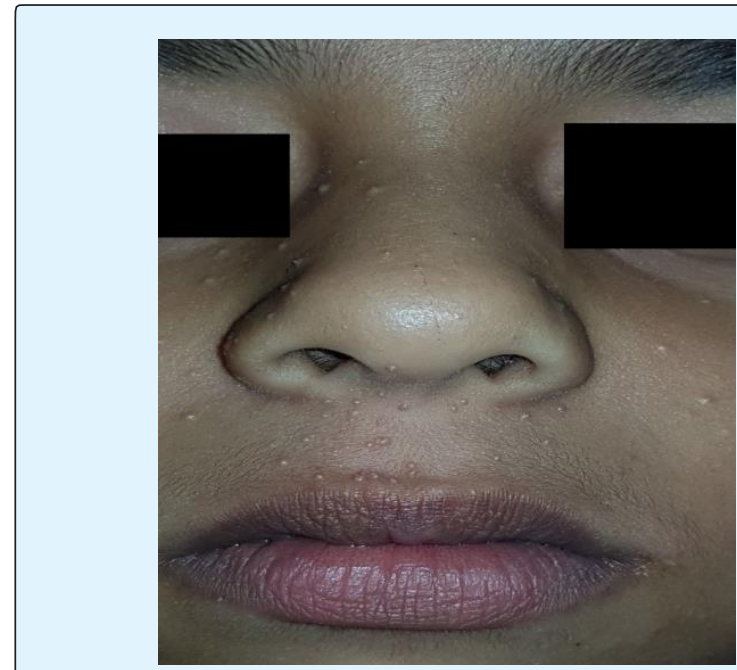

Figure 3: Recurrence of multiple facial molluscums after 4weeks.

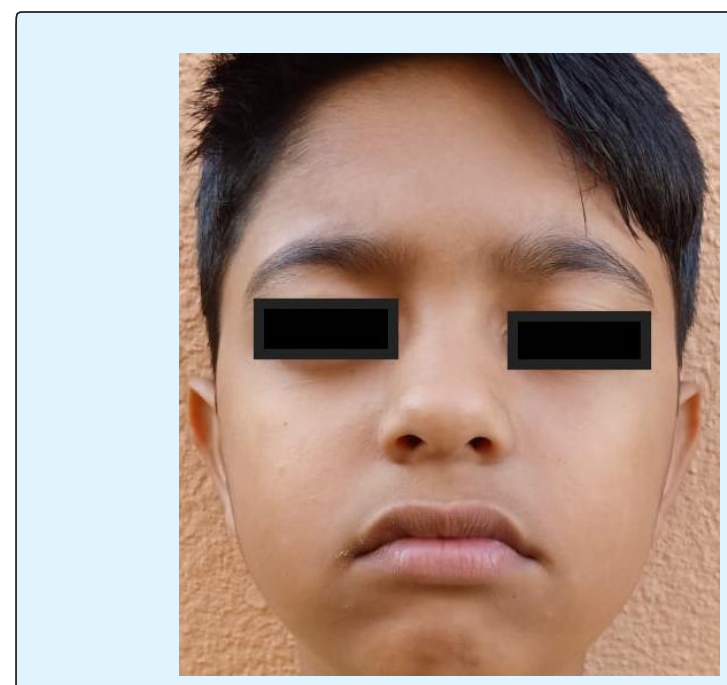

Figure 4: Complete resolution of lesions after 6 weeks. 
He was then given oral zinc $10 \mathrm{mg} / \mathrm{kg} /$ day to prevent recurrence. However the patient still got recurrence of multiple molluscums on face after 4weeks (Figure 3). Our patient was highly reluctant to undergo the same painful procedure again, so we first gave him oral zinc along with topical tretinoin $0.025 \%$ cream with no relief in one month. Then we thought to try a simple oral immunomodulator - syrup ranitidine. We treated him with oral ranitidine syrup $(5 \mathrm{mg} / \mathrm{kg} /$ day in two divided doses) along with oral zinc and topical tretinoin 0.025\% cream. To our surprise, after 15days, patient had 50\% clearance of lesions. After 6weeks, patient had complete clearance of lesions (Figure 4). We continued oral ranitidine and zinc for more 15days and then stopped. There was no recurrence even after 2 months of stopping treatment.

\section{Discussion}

Although MC is one of the most common viral skin infections in children, no scientific evidence clearly favors a specific treatment for MC. In general, any procedures that cause intense pain or are associated with a significant risk of scarring (curettage/cryotherapy/chemical and electrical cauterization) are avoided.

Oral cimetidine(an $\mathrm{H} 2$ receptor antagosnist) is a known oral immunomodulator used in the treatment of MC. It acts by stimulating delayed hypersensitivity. In a clinical study by Dohil, et al. 13 children with molluscum contagiosum were treated with $40 \mathrm{mg} / \mathrm{kg}$ of oral cimetidine once a day for two months and complete resolution was observed in 9 of 13 patients [3]. However, in a double-blind trial comparing placebo treatment with oral cimetidine, no statistically significant differences were observed between the placebo and treatment groups [4].

Ranitidine is also histamine H2 -receptor antagonist, which differs in chemical structure from both histamine and cimetidine [5]. Ranitidine is more potent inhibitor than cimetidine but it does not have cimetidine's antiandrogenic and hepatic microsomal enzyme inhibiting effects [6,7]. It has proven safety profile in pregnancy and lactation, in children and elderly. The drug is very well tolerated and is not associated with any serious adverse reactions or clinically significant drug interactions [8]. Due to its favourable efficacy and tolerability profile, we chose oral ranitidine in our patient as an immunomodulator. While researching for its immunomodulatory action, we found multiple studies showing its utility as immunomodulator in trauma and malignant cancer cases [9-12]. Treatment with ranitidine in head injury patients was associated with a significant increase in CD4+ lymphocytes (33\% to 49\%; $\mathrm{p}<.05$ ) and a significant decrease in CD8+ lymphocytes (41\% to $27 \%$; $\mathrm{p}<.05$ ) compared to placebo. Also, the interferon-gamma production increased from 121 to $269 \mathrm{pg} / \mathrm{mL}(\mathrm{p}<.05)$ in patients treated with ranitidine compared to placebo [11]. Another study of oral ranitidine in colorectal cancer patients revealed that the natural killer-, lymphokine activated killer-, and interferon-alpha stimulated killer cell activity increased significantly in the ranitidine patients compared to the placebo patients $(\mathrm{p}<0.02, \mathrm{p}<$ 0.03 and $\mathrm{p}<0.05$, respectively) [12].

As our patient was reluctant to undergo effective but painful method of curettage again and also due to poor response to topical retinoid, we thought of immunotherapy would be best choice for him for complete clearance of multiple lesions and to prevent recurrence. Owing to the favorable efficacy and safety profile, we chose oral ranitidine over cimetidine. To our surprise, our patient had complete clearance of multiple molluscums on face within 6weeks of oral ranitidine $(5 \mathrm{mg} / \mathrm{kg} /$ day) therapy, which was given for 8weeks and then stopped. Recurrence was not observed even after 2 months of completing therapy.

\section{Conclusion}

Oral ranitidine should be considered as a simple, effective and safe alternative treatment for widespread, or recurrent MC in immunocompetent children. It may be particularly useful for young children who cannot tolerate painful methods like cryotherapy or curettage or repeated visits for chemical application. The drug is thought to have an immunostimulatory effect by increasing CD4+ lymphocytes and decreasing CD8+ lymphocytes. Lesions of molluscum may also resolve spontaneously; hence a double-blind, placebo-controlled study is needed to confirm the efficacy of ranitidine.

\section{References}

1. Gerlero P, Hernández-Martín Á (2018) Update on the Treatment of molluscum Contagiosum in children. Actas Dermosifiliogr 109(5): 408-415.

2. Braue A, Ross G, Varigos G, Kelly H (2005) Epidemiology and impact of childhood molluscum contagiosum: a case series and critical review of the literature. Pediatr Dermatol 22(4): 287-294. 


\section{Clinical Dermatology Open Access Journal}

3. Dohil M, Prendiville JS (1996) Treatment of molluscum contagiosum with oral cimetidine: clinical experience in 13 patients. Pharmacol Ther 13(4): 310-312.

4. Antony F, Cliff S, Ahmad A, Holden C (2001) Doubleblind placebo-controlled study of oral cimetidine treatment for molluscum contagiosum. Br J Dermatol 145: 122-129.

5. Dawson J, Richards DA, Stables R, Dixon GT, Cockel R (1983) Ranitidine--pharmacology and clinical use. J Clin Hosp Pharm 8(1): 1-13.

6. Florey K (1986) Analytical profile of drug substances. $10^{\text {th }}$ (Edn.), Academic Press, London, UK, pp: 15; 533561.

7. Brogden RN, Carmine AA, Heel RC, Speight TM, Avery GS (1982) Ranitidine: a review of its pharmacology and therapeutic use in peptic ulcer disease and other allied diseases. Drugs 24(4): 267-303.

8. Pahwa R, Shilpa Sharma S, Kumar V, Kohli K (2016) Ranitidine hydrochloride: An update on analytical, clinical and pharmacological aspects. J Chem Pharm Res 8(7): 70-78.

9. Hahm KB, Kim WH, Lee SI, Kang JK, Park IS (1995) Comparison of immunomodulative effects of the histamine-2 receptor antagonists cimetidine, ranitidine, and famotidine on peripheral blood mononuclear cells in gastric cancer patients. Scand J Gastroenterol 30(3): 265-271.

10. Nielsen HJ, Nielsen H, Moesgaard F, Tvede N, Klarlund $\mathrm{K}$, et al. (1990) The effect of ranitidine on cellular immunity in patients with multiple myeloma. Cancer Immunol Immunother 32(3): 201-205.

11. Rixen D, Livingston DH, Loder P, Denny TN (1996) Ranitidine improves lymphocyte function after severe head injury: results of a randomized, double-blind study. Crit Care Med 24(11): 1787-1792.

12. Nielsen, H, Hammer J, Gronvall S, Monrad H, Grindsted J (1996) The effect of ranitidine on immune function, tumor response and survival in patients with liver metastases from colorectal cancer. GI Cancer 1: 183-190. 